\title{
Ace Your Accounting Classes: 12 Hints To Maximize Your Potential
}

\author{
W. David Albrecht, Bowling Green State University
}

\begin{abstract}
Many students experience difficulties when they try to get good grades in their accounting classes, and they are searching for answers. There is no single answer. Getting a good grade in an accounting class results from a process. If you know and understand the process-and can apply it-then your chances are much improved for getting a good grade. I recommend a process that includes twelve steps: (1) know what the professor expects, (2) be your own teacher, (3) work hard from the first day, (4) attend every class, (5) take good notes, (6) participate in class, (7) read the textbook several times, (8) look for patterns, (9) do the homework, (10) study with a friend, (11) study long and hard for each exam, and (12) live healthfully.
\end{abstract}

\section{INTRODUCTION}

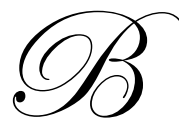

renda was just one of about 100 students spread across three sections of first semester Intermediate Accounting in the fall semester, 1992. She was neither quiet nor outspoken, and I regret to say that through the first third of the course I barely noticed her. When I handed back student answers for the first midterm exam, a red $\boldsymbol{D}+$ dominated hers.

As I collected student exam answers at the end of class, I noticed Brenda was clearly peeved. She blurted out that she would not ever do that poorly on an exam again. She firmly set down her exam, and then marched stridently out of the classroom.

"Fat chance," I thought. A low exam grade is serious, frequently symptomatic of a persistent disease called poor study habits. Although most students hope to turn it around, they don't. They can't, because they simply don't know how to study properly for an accounting class. The disease can be cured, but it takes a change in an outlook as well as considerable effort.

Brenda fooled me. She became more vocal in class, and soon her comments reflected an amazing insight. She had the high score on each of the two remaining exams, and finished with one of the highest scores overall and a very solid $\boldsymbol{A}$. What a fantastic turn around! She later confided that she initially underestimated the course. Her first exam score was a wake-up call, signaling the need to get serious.

She's one of my all-time favorite students because she became such an active learner. Her grade of $\boldsymbol{A}$ was a by-product of a greater reward - thorough mastery of accounting topics and a keen understanding of how to use her knowledge. Now a successful tax specialist, she occasionally returns to campus speaking on the desirability of an accounting career and how to be successful at school and on the job.

\section{HOW TO ACE YOUR ACCOUNTING CLASSES}

1. Know what the professor expects.

2. Be your own teacher.

3. Work hard from the first day.

4. Attend every class.

5. Take good notes. 
6. Participate in class.

7. Read the textbook several times.

8. Look for patterns.

9. $\quad$ Do the homework.

10. Study with a friend.

11. Study long and hard for each exam.

12. Live healthfully.

Through the years, several dozens of students have asked me how to fare better (i.e., get better grades) in their accounting classes. I am able to offer general advice because accounting classes invariably are driven by content and hence have many similarities. The primary focus is for students to acquire a detailed knowledge of the rules. But that's not all, students should also understand the accounting rules and develop skill in applying them. What follows is my advice for acing a content-driven accounting class.

\section{KNOW WHAT THE PROFESSOR EXPECTS}

Almost without exception, every accounting professor cares deeply for his/her students. We are anxious to see students do well. We are excited to assign high grades (i.e., $\boldsymbol{A}$ or $\boldsymbol{B}$ ), and we regret having to assign low grades (i.e., $\boldsymbol{D}$ or $\boldsymbol{F}$ ). So why is the grade point average for most accounting classes so low (typically near the lowest at many universities)?

Accounting professors have high expectations, and seldom make exceptions when assigning grades. These high expectations are a product of both our history and our make-up. Successful business operations have always depended upon accurate records and summary financial reports. An essential job qualification for accountant or bookkeeper is a sharp eye for detail, to be a very precise individual. Accounts otherwise would be filled with errors. In professional schools of business, accounting professors usually have a significant amount of practical experience and have reinforced their tendency toward precision. With a keen sense of discernment, we read test answers and mark as incorrect any that aren't right on the mark. Unfortunately, far too many students are imprecise in their knowledge and understanding. The following descriptions will help you understand an accounting professor's expectations.

Accounting professors generally have well-defined standards when assigning grades for a course or test. The grade of $\boldsymbol{A}$ requires excellent performance on exams, quizzes and homework. Exam scores are perfect, or very close to perfect. This is doable. I regularly get at least a dozen perfect exams each semester. An $\boldsymbol{A}$ student has risen far above memorization and knowledge recall. An $\boldsymbol{A}$ student has identified and learned patterns and is able to apply them correctly to any question the professor asks. An $\boldsymbol{A}$ student wants tough test questions to show how thoroughly he or she has mastered the concepts and material. Such a student expects the grade of $\boldsymbol{A}$ when taking a test or course, virtually daring the professor to ask a question that can't be answered. The professor's high expectations have become the student's.

The grade of $\boldsymbol{B}$ requires very good performance. Students really know their stuff, having a very good understanding of the big picture and all concepts and procedures. They receive a $\boldsymbol{B}$ because on test questions they make too many small errors on too many topics. Of course, work having patterns of errors is by definition imprecise, and the grade of $\boldsymbol{A}$ requires precision.

$\boldsymbol{C}$ stands for competent, not consolation prize. I know many students don't like a grade of $\boldsymbol{C}$, but accounting professors believe it is nothing to be ashamed of. Many students receiving a $\boldsymbol{C}$ are inconsistent, a few errors on some topics and many on others. A common characteristic of students receiving a $\boldsymbol{C}$ is that they are only familiar with the material. They can recognize correct answers, but they have difficulty in creating them. When listening to a professor's lecture and reading the textbook, accounting topics make sense to them. However, they are lost when their textbook or notes are not in front of them. This is because they have not picked up on the recurring patterns of accounting. They have learned solutions, not processes. Students receiving a grade of $\mathrm{C}$ often try to memorize everything (text examples and homework solutions). When studying like this, they get tripped up two ways. The 
sheer volume of the material overwhelms them and they get confused recalling snippets at the wrong time on the exam. A second adverse result occurs when the professor asks an exam question in a different fashion from the textbook examples, the student is unable to adapt.

Other students are not very well acquainted with the material. If a student can show a fair understanding on more than one topic, he or she can usually receive the grade of $\boldsymbol{D}$. A grade of $\boldsymbol{F}$ is for when test performance is very far from perfect on most (if not all) test questions. A professor looks at such tests and laments the student has learned nothing of lasting significance from the course so far.

Now that you know what is expected for a high grade, the following hints explain how to get it. Acing your accounting class is an attainable goal. It depends less on high intelligence or on brute effort than on smart study. If you are smart enough to get into college, then you are smart enough to do well in your accounting classes. If you follow the remaining hints, then you greatly increase the likelihood that your accounting professor will be assigning you the grade of $\boldsymbol{A}$.

\section{BE YOUR OWN TEACHER}

As a student, your primary goals in learning are to gain (1) knowledge or (2) understanding of or (3) skill in (Merriam-Webster). Your professor is formally charged as your teacher. Given heavy teaching loads, though, it is unlikely that you will have anything more than brief and sporadic occasions in which your professor personally instructs you or assesses your learning status. Is all lost? No, not at all. The true value of a collegiate education is the journey of discovery followed to learn the material set before you. In the future you may forget some of the knowledge or it may be superceded, but your experiences cannot ever be taken away.

In a content driven class, the functions of your professor are (1) to present the course content you are supposed to learn, and (2) to explain it so that there should be no confusion about it on your part. How you go about it is up to you! You should go about it by studying smartly. It is not the professor's function or responsibility that you should learn the material, only that it be presented in a learnable manner. Perhaps you have heard the words of wisdom, 'A horse can be led to water, but it cannot be forced to drink.'

Studying smartly starts when you take stock of how much prior knowledge and understanding you possess when given something to learn. Getting from here (point B, C, D, or F) to complete and precise mastery (point A) must be planned for. Of course you should work hard from the first day (\#3), attend every class (\#4), take good notes (\#5), participate in class (\#6), read the textbook several times (\#7), look for patterns (\#8), do the homework (\#9), study with a friend (\#10), and study long and hard for each exam (\#11). However, the amount of effort you expend on each one is up to you. So, how much effort should each one take? It depends on you. As you study, you should continually assess your progress and your up-to-the-hour level of knowledge. If you don't monitor your own learning, there is no one to do it for you. You must accept the responsibility and be your own teacher.

\section{WORK HARD FROM THE FIRST DAY}

Students who are current in the course - avoiding procrastination - invariably do better. They study from the first day and don't let up until the course is over. Why? Study time spread over several days or weeks is more efficient and effective than cramming. Psychologists have discovered that time spent cramming results in poorer recall than the same amount of study time spread over a period of days or weeks. Spread out over time, students have more opportunities to think about the material, contemplate potential applications, associate knowledge with concepts and let their subconscious mind work on learning. In other words, there is a higher upside.

Invariably, exams and assignments for other courses fall due at the same time as an accounting exam. If students intended to rely on cramming, their anxiety and stress levels increase when there is simply too much to learn in the allotted time. Anxiety and stress have been consistently shown to impede frontal lobe activity and learning. Consequently, students have more difficulty in getting the grade they want. 
It can be very difficult to catch up once behind. Students that get behind have at least twice the work load of students that are caught up, because they must simultaneously study both earlier and current topics. Having to learn both at the same time usually results in learning both poorly, because later topics course frequently build on the earlier topics. If you don't learn the first topic, then it is nearly impossible to learn the second topic and the third topic cannot be learned, only memorized. For example, students that put off learning present and future values have difficulty in learning other topics that use it (e.g., long-term liabilities, leases and pensions).

\section{ATTEND EVERY CLASS}

There is a high correlation between regular class attendance and earning a good grade in a course. Said another way, cutting a lot of classes will likely cost you at least one letter grade. Class is a great opportunity to "sit at a professor's feet" and hear his/her perspective on the topic of the day. Chances are that the professor has three degrees in accounting (Bachelor, Master, Ph.D.), and has picked up many insights that will be passed along in class.

Another reason for everyday attendance is that most professors focus class presentations on the most difficult topics, so it's likely that many questions will be answered during class. I recommend thinking of time spent in class as concentrated study time. When in class, there should be no reason to think of anything but accounting. If your mind wanders while in class, yank it back. If you are bored by the professor, spend class time thinking of how you could be more interesting presenting the same material.

For any who believes he or she already know everything about the scheduled topic, there is still a benefit to attending a class. Class coverage reinforces material already studied, an important key to learning. When more time is spent going over key topics, the deeper the understanding, the better the recall and the higher precision will be when taking an exam.

Finally, most professors focus on their most familiar topics and issues. Most professors also test on their most familiar topics and issues. Do you see the link? If these reasons don't work for you, remember that tuition has been paid and you might as well get your money's worth by attending every class.

\section{TAKE GOOD NOTES}

All students should take good notes in class, whether the format is lecture or discussion. Said another way, taking good notes is essential to getting a better grade. Research has shown, however, that most students don't take good notes. There are several ways to improve notetaking.

First, recognize that you should have at least one full page of handwritten notes for each 25 minutes of class. Second, your notes should capture the professor's description of each accounting rule and all related examples. Your professor expects you to study and learn the examples, so make sure you don't miss any.

Write down everything put on the board when your professor lectures. If the professor puts it the board, he or she definitely wants you to learn it. Unfortunately for note takers, not all key points get written on the board. So listen carefully, identify the professor's conclusions, and get down all key points. When the professor works a number-intensive problem at the board, note both the number and how the computation is performed.

The most difficult type of class to take notes for-let alone learn anything-is one in which the professor lectures and relies upon Microsoft PowerPoint. There are several reasons for this, but two are described here. First, more than one hundred research studies have documented a phenomenon called death by PowerPoint. In a PowerPoint class, all (or most) of the communication and intellectual activity is being performed by the professor. Consequently, merely staying awake is a noteworthy accomplishment. Second, PowerPoint enables the professor to bombard students with much more detail than possible when the professor is limited only to the spoken word. 
The best way to take notes in a PowerPoint class is simply not to take any. Rely upon the file of slides provided by the professor. If the professor's PowerPoint slide file is incomplete (i.e., it only contains a section's main heading or questions), then focus on reading the textbook.

Taking notes is different in a discussion-oriented class, as the how-to's will be offered by students, not the professor. In a lecture class, concentrate on what professor says, but in a discussion class you must focus on the professor's questions. Always write down the professor's questions as they provide a blue print for the entire discussion. Don't be reticent about asking a professor to repeat a question, as the professor will think of you as a good student. For the student discussion offered as a question's answer, listen and evaluate before adding anything to your notes. This is because discussion points raised by students can be correct or incorrect. Upon hearing something worth noting, write down only a few phrases. Elaborate on these immediately after class while they are fresh in your mind.

Notes should be rewritten within 24 hours of class! Why? One benefit is that it reinforces the key points made in class. Another is that the notes will be properly organized and neat, which should make study for the next exam all the easier. When finished with rewriting your notes, you should have a complete story as to what occurred in class. If there is not enough time both to rewrite your notes and read the textbook, you should rewrite your notes.

\section{PARTICIPATE IN CLASS}

Given the same amount of study time, students participating in class learn the material better than those not participating. In other words, class participation can help you get a better grade. A proper frame of mind to adopt is to seize ownership of the class. It is your class and you should care about everything that happens in it. When the professor is lecturing, imagine that he or she is speaking directly to you! In addition, the professor expects a response, from you. There are several ways to respond. Asking questions and volunteering answers (don't be afraid of a wrong answer) are two ways. Writing down your thoughts is another. Your professor might be flexible enough to permit you to ask questions or explain something by whispering to another student. Be courteous and don't disrupt the class.

If the professor uses presentation software (e.g., Microsoft PowerPoint) and places the file on-line prior to class, then download it and review it prior to class. This makes it possible for students to formulate questions in advance so they can ask them at appropriate times. Prior review of the class outline enables students to be ready to move forward with the professor from the first minute of class. Ask questions in class and volunteer answers to the instructor's questions. Don't be afraid of wrong answers, as you can learn from your mistakes.

\section{READ THE TEXTBOOK SEVERAL TIMES, AND READ IT WELL}

Reading an accounting textbook is much like reading an encyclopedia. It is knowledge and factually oriented, and difficult to swallow in one gulp. No chugging is allowed. Chapters are long with about 30 pages of words and numbers and 20 pages of homework problems-fifty pages in all! Critical reading is the key to learning the detail-oriented material in long chapters.

The first reading of the chapter (about 20 minutes) is more of a leisurely skim. The goal is to identify the chapter's topic. The second reading should be very thorough, taking two to four hours. Jot notes in the margins, use a highlighter, and take notes. Each example in the text should be worked by hand. Later, when doing homework problems, refer back to the relevant pages (the third reading). After the topic has been covered in class, read the chapter a fourth time. The goal now is to tie everything together. Observe how key concepts and principles (e.g., asset characteristics, matching principle) are reflected in the chapter's coverage. When studying for an exam, there is no need to again read the chapter. Use it only as a reference. 


\section{LOOK FOR PATTERNS}

After taking good notes in class and critically reading the text book, students are in good position to identify the key patterns. A pattern is a form, template, or model. Applied in accounting education, a pattern is a general set of rules used to solve homework and exam problems. When studying a general topic area (such as the accounting for inventories), the goal is to develop a summary of the rules broad enough to cover most homework and exam problems and specific enough to provide guidance for dealing with accounting's details.

Start by creating a numbered list of steps for working a problem. Then, with this list as your guide (i.e., the textbook is closed), start working homework problems. If you can't accurately complete a problem with your initial lis, then add a few words of explanation or another point. If you have worked three or four problems and you haven't used one of your points, then please delete it. Your goal is to develop light-weight but heavy-duty patterns.

\section{DO LOTS OF HOMEWORK}

Accounting rules are man-made. Not always self-evident, they must be learned by a process that includes repetition for reinforcement. When I was a young accounting student, a graduating senior gave me excellent advice. He advised me to work every exercise and problem in the text book. I eventually found this to be an attainable goal. In a little more than four hours (spread over two or three days), I could organize the key parts of the solution to all exercises and problems. I recommend all accounting students do the same.

\section{STUDY WITH A FRIEND}

Wouldn't it be great if you could find a non intimidating environment in which to learn? You can, by studying and working problems with a friend. The major benefit from working with a partner is to gain practice in explaining what you know. You are asked to explain what you know on exams, so any practice you can get will help. Therefore, don't pick the smartest person in the class with which to partner. A second benefit from working with a partner is that you can listen and evaluate what is being said to you. In class, a natural assumption is that the professor is always correct, but not so with a study partner. Being forced to think while you listen is invaluable, and every bit as important as thinking before you speak.

\section{STUDY LONG AND HARD FOR EACH EXAM}

Acing your accounting exams takes real work and a lot of it. After putting into practice the preceding nine hints and the date of the exam is fast approaching, you are ready for exam preparation. I recommend about 15 hours of study just for exam purposes. Fifteen hours seems like a lot of time, and it is. The benefits that accompany an A usually come with high opportunity costs. It's a lot easier to hang out with friends, watch videos, watch TV, play Xbox or other games, or just have fun, than to spend time studying an encyclopedic subject. Also, like many other students you probably spend an average of 30 hours per week at a job. Never-theless, you defeat an important reason for going to college if you don't adequately prepare for a test. You must somehow strike a balance between the hours you spend working and the hours you can spend studying. You must have self-discipline and not partake of your normal recreational activities until after the test.

The first step in preparing for a test is to identify what the professor expects you to know and how well. This step is fairly easy if your professor has distributed an exam preparation guide. This guide generally lists the major topics to be tested, along with the type of question format. You should study everything on it, and nothing else. If your professor has said simply, "You are responsible for everything covered either in class or in the text book," then you have your work cut out for you. Go through your notes and form a checklist by listing all topics and sub-topics covered. For example, coverage of cost-volume-profit (CVP) from managerial accounting might have the following eleven item checklist: Using the contribution margin, compute the number of units needed to (1) break even, (2) reach a target profit of $\mathrm{x}$ dollars, (3) reach a target profit as a percentage of sales revenue; using the contribution margin percentage (CM\%), compute the amount of total sales revenue needed to break even, (5) reach a target profit of $\mathrm{x}$ dollars, (6) reach a target profit as a percentage of sales revenue; (7) compute the number of units 
needed for the equal profit between different cost structures; (8) perform CVP analysis when variable costs per unit; (9) perform CVP for multiple products; (10) compute sales price when number of units, costs, and target profit are known; (11) explain the reasons why CVP is used. If your test is to cover several chapters, your check list could easily have dozens of items.

The second step in preparing for a test is to identify the test format. If your test is going to be multiple choice, your study will necessarily be different than if your test is going to be problems and/or written answers. For a multiple choice test, you should definitely study every topic covered either in the textbook or in class, but you don't need to study any topic as deeply as you would if you were to have a different type of test format. You only need to be able to recognize correct answers. Professors use multiple choice questions to test your breadth of knowledge. That is, you are usually tested to see if you are familiar with almost every topic covered. Multiple choice questions don't assess application or interpretation. Does your professor have a reputation of using a textbook's bank of multiple-choice test questions? If so, your focus should be to study the book. Does your professor write his or her own questions? If so, your focus should be to study your notes. For a multiple choice test, the best study aid is the use of flash cards. These take a significant amount of time to make, but they are worth it as you drill yourself on the knowledge to be covered on the exam.

Work old exams, go over notes, and work new problems. Concentrate on principles and patterns, and being able to apply them in varied settings. It is not a good idea to work and rework the homework problems because you will have them memorized after you look at them two or three times. It is better to work new homework problems.

\section{LIVE HEALTHFULLY}

The final hint is often overlooked by students, to the detriment of their GPA and general physical health. Your health must be good to think well and learn effectively. Failure to live healthfully makes it more difficult to get good grades in accounting. Your frontal lobes (the portion of the brain where cognition and learning take place) can react negatively to six lifestyle factors. More important, any of these six negative lifestyles will degrade your quality of life and significantly shorten your expected life span.

- $\quad$ Sleeping less than $8 \frac{1}{2}$ hours per day on a regular basis. Over a prolonged period of time, your expected life span will be shortened five to eight years for each hour you are short of the daily goal. Simply put, regularly get a full night of sleep.

- $\quad$ Staying up late at night. Humans sleep better and more healthfully at night than during the daytime. Getting at least two hours of sleep before midnight is essential to a high quality night of sleep. You will most likely guarantee a poor grade if you stay up late the night before a test. Always staying up late can shorten your expected life span by at least two years. Simply put, go to bed early.

- $\quad$ Drinking any beverage other than water. Regularly drinking any of the following beverages can reduce your expected life span by several years and makes it difficult for your brain to function properly: caffeinated (coffee, tea, cola), carbonation, artificially sweetened, sugar added and alcoholic. Simply put, you should drink two or three quarts of water daily.

- $\quad$ Eating foods containing meat/fish, dairy products and animal fats. Vegans on average live fifteen years longer than those regularly eating a diet heavy in meat, dairy and animal fats (and they enjoy life more). Eating foods rich in refined sugar and preservatives also makes it more difficult for you to get a good grade in your accounting classes. World class professional athletes and physically attractive entertainers have known for years about the link between a vegan diet and excellent physical health. You can learn from their experience. Simply put, eating meals consisting of fruits, grains, vegetables and nuts is the secret to living a long, healthy and productive lifestyle.

- Avoiding exercise. Americans live a busy lifestyle, and students are no exception. When time is short, busy people frequently drop exercise from their daily routine. This is unfortunate, because those that actively exercise have healthier brains. In addition, exercise reduces stress, (stress is abundant on college campuses), and less stress leads to better thinking. Research studies report that a balanced program of aerobic exercise (jogging/walking) and strength training is more efficient and effective in maintaining physical and mental health. On average, walking briskly three to five miles for six days per week along 
with 30 minutes of upper and lower body strength training (three times per week) will keep your brain in thinking trim and contribute to better grades.

- Avoiding sunlight. Those who spend most of every day inside tend to have a higher rate of depression, more difficulty in getting to sleep and poorer health. Sunlight is the principle source of vitamin D. A complete absence of vitamin D is fatal. A majority of adult Americans are so deficient in vitamin D that they experience significant health problems as a result. Vitamin D dietary supplements do not adequately replace natural sunlight, although many benefit from short doses of ultra high intensity natural sunlight lamps. Never-the-less, 20 minutes per day should be spent outside during daylight hours.

\section{CONCLUSION}

Here you have them, the twelve hints that will help you ace your accounting course or courses. I wish you well as you make the journey to better grades.

\section{NOTES}

